\title{
A comparison of response modes on the perception of linear extent*
}

\author{
H. R. SCHIFFMAN \\ Rutgers. The State Liniversity. . Vew Brunswick. I.J. 08903
}

The influence of mode of response on the perception of linear extent was investigated by comparing the length reports given by a verbal-response mode absolute judgment with a length-matching response mode. The stimuli were five different lengths, ranging from 51 to $559 \mathrm{~mm}$, and they were shown at two durations, 0.5 and $5.0 \mathrm{sec}$. The results indicate that there is not a consistent effect of the response mode on the stimulus length and stimulus duration. It is suggested that the choice of response mode be primarily determined by the demands of the experimental testing conditions and apparatus.

Research on the perception of linear extent generally requires one of several methods for extracting the S's response. Two of the most often applied experimental procedures for reporting responses are matching techniques-making explicit comparisons or adjustments between two simultaneous or sequentially presented stimuli-and absolute judgments, in which a $\mathrm{S}$ identifies the metric dimension of a particular stimulus with a single value or number. usually some physical measure (Garner \& Hake. 1951). These response methods have also been labeled by Over (1963) as judgments and estimations, respectively. In general. these two classes of response modes involve quite different procedural conditions: therefore, it is possible that the resultant dependent values reflect the operations of different psichological processes. As a consequence, the possibility exists that the perception of the same stimuli reported by different techniques may produce different findings.

In a number of instances, different investigators, presumably focusing on the same general issue, have employed either of these different response modes. For example. Bolles \& Bailey (1956), McKennell (1960), Schiffman (1967), and Gogel \& Newton (1969) studied familiar size utilizing an absolute estimate response (verbal response in inches), whereas Slack (1956), Fillenbaum, Schiffman. \& Butcher (1965), and Leibowitz \& Harvey (1969) used similar stimuli but restricted their Ss' response mode to a matching task. Because different experimental designs and response procedures were employed, the findings are not directly comparable and no attempts have been made to compare the effect of response conditions. In a related report, Churchill (1962) compared the size estimates of objects, made verbally in inches, with judgments resulting from a reproduction procedure (line drawings). Unfortunately.

* This research was supported by funds from the Research Council of Rutgers. The State Cniversity (Grant 07-2109) and a Biomedical Science Support grant from the United States Public Health Serice. Appreciation is due James Wales for the testing of all $S S$ and Randy Stec and Robert Mulligan for the analyses. the results were reported only as correlation coefficients. which precludes direct comparisons on the basis of response reliability or magnitude.

These comments are by no means restricted to familiar stimuli. A similar case-that of the same general phenomena or variable assessed by different response modes-can be identified with the perception of simple line lengths. For example. Epstein (1966) and Colhart (1969) had Ss estimate relatively small lengths in inches. whereas Baird (1963), using similar lengths. had Ss make size judgments by adjusting a comparison stimulus. Another example occurs with context or series effects. There are a number of reports that the effects of responding to a series of stimuli produces an effect on the perception of individual stimuli (e.g. Krantz \& Campbell. 1961: Miller \& Engen, 1960). For example, the same stimulus will be estimated differently if it appears within a series of large lines than if it appears within a series of small lines. Most relevant to the present discussion are the research reports that the response mode has a direct effect on the results. Specifically. it has been reported that absolute judgments manifest the effects of a context bias. whereas a matching task does not (Schiffman, Goldstein. \& Aroksaar. 1970). In short. different response methodologies lead to different conclusions.

It is clear that how a $\mathbf{S}$ makes his response of linear extent is a potentially important issue. and data on a direct comparison are needed. Accordingly. the present study was designed to examine the reliability of responses made by two response conditions with the additional methodological consideration of stimulus duration.

\section{METHOD \\ Subjects}

Forty-eight male volunteers from an introductory course in psychology served as Ss. All Ss had uncorrected normal vision.

\section{Stimuli}

The stimuli were positive transparencies. each of which projected a 5-mm-wide black horizontal line against a white background. The projected line lengths in millimeters were 51. 178, 305. 432. and 559 .

\section{Apparatus}

The stimuli were projected from an automatic projection tachistoscope (Lafayette Model KT-800. with Alphax shutter). and cast a $114 \times 76 \mathrm{~cm}$ image at eye level in the frontal-parallel plane on a $122 \times 91 \mathrm{~cm}$ rear-projection screen located about $1 \mathrm{~m}$ from the $S$.

A length-matching apparatus was located directly in front of the $S$ on a table separating him from the viewing screen. It consisted of a black wooden base. $20 \mathrm{~cm}$ wide $\times 1 \mathrm{~m}$ long. with $23-\mathrm{cm}$ vertical rods at either end that supported a $25-\mathrm{mm}$-wide black wooden strip that spanned the length of the base. Two adjustable markers. $6 \mathrm{~mm}$ wide. straddled the strip: the inside 
Table 1

Means and Standard Deviations of Reports by Response Mode and Stimulus Duration

\begin{tabular}{|c|c|c|c|c|c|c|c|}
\hline \multirow[b]{2}{*}{ Response Mode } & & \multirow{2}{*}{$\begin{array}{c}\text { Duration } \\
\text { (Sec) }\end{array}$} & \multicolumn{5}{|c|}{ Stimuli (mm) } \\
\hline & & & 51. & 178 & 305 & 432 & 559 \\
\hline Verbal Response & $\begin{array}{l}\text { Yean } \\
\text { SD }\end{array}$ & 0.5 & $\begin{array}{r}39.0 \\
6.3\end{array}$ & $\begin{array}{r}151.6 \\
22.9\end{array}$ & $\begin{array}{r}-60.7 \\
\therefore 4.2\end{array}$ & $\begin{array}{r}359.4 \\
70.7\end{array}$ & $\begin{array}{l}502.6 \\
103.9\end{array}$ \\
\hline Verbal Response & $\begin{array}{l}\text { Mean } \\
\text { SD }\end{array}$ & 5.0 & $\begin{array}{r}41.3 \\
8.5\end{array}$ & $\begin{array}{r}160.1 \\
42.6\end{array}$ & $\begin{array}{r}282.7 \\
31.7\end{array}$ & $\begin{array}{r}393.0 \\
34.9\end{array}$ & $\begin{array}{r}501.0 \\
67.6\end{array}$ \\
\hline Length Match & $\begin{array}{l}\text { Mean } \\
\text { SD }\end{array}$ & 0.5 & $\begin{array}{l}48.5 \\
11.9\end{array}$ & $\begin{array}{r}158.0 \\
21.5\end{array}$ & $\begin{array}{r}248.6 \\
27.6\end{array}$ & $\begin{array}{r}343.2 \\
69.1\end{array}$ & $\begin{array}{r}471.8 \\
59.5\end{array}$ \\
\hline Length Match & $\begin{array}{l}\text { Mean } \\
\text { SD }\end{array}$ & 5.0 & $\begin{array}{l}44.1 \\
12.7\end{array}$ & $\begin{array}{r}158.4 \\
31.1\end{array}$ & $\begin{array}{r}246.4 \\
37.4\end{array}$ & $\begin{array}{r}382.6 \\
57.2\end{array}$ & $\begin{array}{r}501.6 \\
68.9\end{array}$ \\
\hline
\end{tabular}

edges of the markers were painted white. in a contrast with the black outside edges. A scale attached to the side of the strip not facing the $S$ was used by E for measuring the Ss' response. Room illumination was approximately $6 \mathrm{fi}$.

\section{Design and Procedure}

There were three experimental variables. The Ss were assigned randomly to each of two levels of two of the experimental variables with repeated measures taken of the third variable. This resulted in a 2 by 2 by 5 factorial design with four independent groups. $12 \mathrm{Ss}$ per group.

The first experimental variable was stimulus length. Each $\mathrm{S}$ was individually shown the stimuli one at a time for three presentations. The order for the total of 15 presentations 15 stimuli shown 3 times) was randomly determined for each $S$. The mean of the reported values for the three presentations of each stimulus was taken as the $S$ 's response for that stimulus. These stimuli were run for each combination of the two other experimental variables.

The second experimental variable was mode of response: A verbal-response group was instructed as follows: "You will be shown. one at a time. a series of slides: on each slide there is one horizontal line. Your task is to estimate the length of the line in inches. Before the presentation of each slide I will call out 'ready. Please call out your length estimation to the nearest ${ }^{{ }^{1}+}$ of an inch when I say "respond." A length-match response group was instructed to use the length-matching apparatus to produce a response. Their task was to move the two markers together or apart. so that the distance between the white inside marker edges appeared to match the length of the line that was shown. The $E$ alternated moving the markers together or apart after each response.

The third experimental variable was stimulus duration: the exposure interval was set at $0.5 \mathrm{sec}$ for a short-exposure group and at 5.0 ses for a long-exposure group.

The interstimulus interval for all groups was $15 \mathrm{sec}$. Each $\mathrm{S}$ was shown three practice slides consisting of intermediate line lengths prior to the experimental session.

\section{RESULTS AND DISCUSSION}

A summary of the main results is given in Table 1. Based on an analysis of variance. the main effect of stimulus length was significant $(\mathrm{F}=493.4 \mathrm{df}=4 \cdot 176$. $p<.0001)$. Main effects due to response mode or stimulus duration were not reliable. There was a significant interaction between stimulus length and response mode $(F=3.3 . \mathrm{df}=4 / 176 . \mathrm{p}<.05)$. between stimulus length and stimulus duration $(\mathrm{F}=4.2 \mathrm{df}=$ $4 / 176 . p<.01$ ). and between stimulus length. stimulus duration. and response mode $(F=9.6 . \mathrm{df}=4 / 176$. $\mathrm{p}<.01)$. The interactions indicate that stimulus duration and response mode are differentially affected by the stimulus length. These effects are graphically presented in Fig. 1. where reports by stimulus length are plotted for response mode and stimulus duration. There does not appear to be a consistent effect across response mode and Stimulus Duration by Stimulus Length. Further, the variability of reports. presented as-SDs in Table 1. do not show any systematic trends with response mode or with stimulus duration. Predictably. SDs increase with increases in stimulus size. Of subsidiary interest is that. in all conditions, the size reports were underestimations of the measured size of the stimuli.

While the nonsignificant mode or response main effect suggests that response condition is not a critical variable in designing experiments of this sort on size perception. it should not be concluded that the two response modes

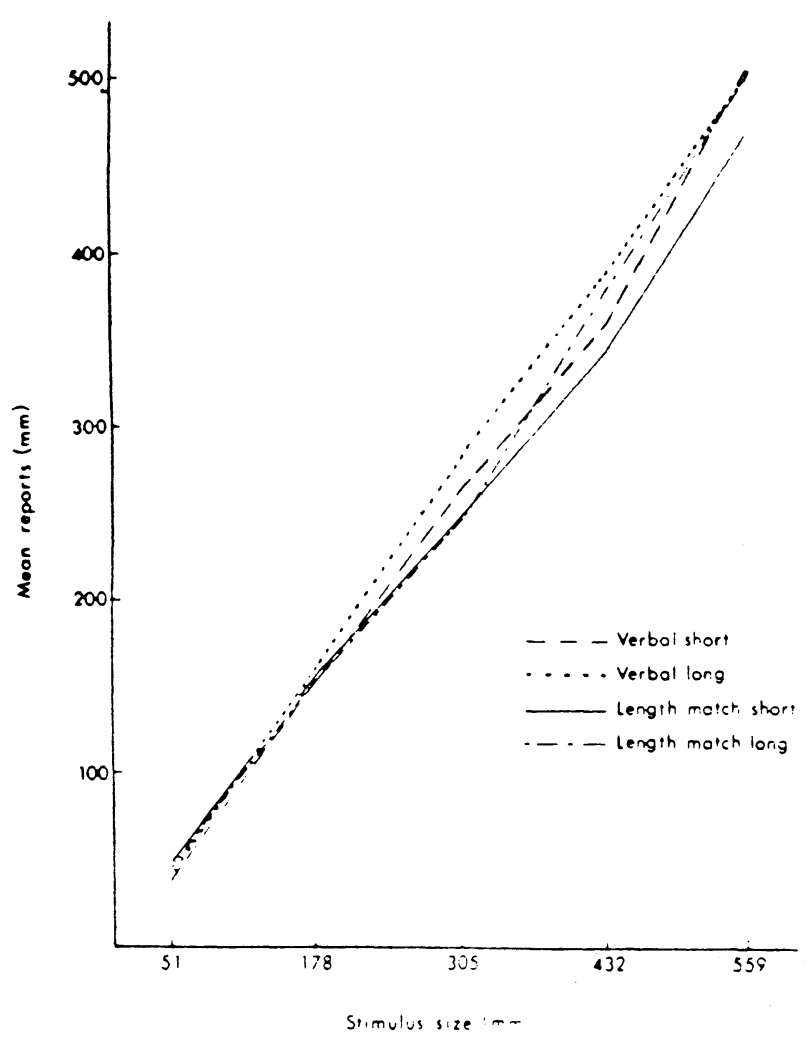

Fig. 1. Yean reports of stimulus length for mode of response and stimulus duration. 
studied are identical in all cases. There are numerous procedural and perhaps pstchological differences in their use. Moreover. under the stimulus conditions for producing context effects (e.g.. Krantz \& Campbell. 1961: Schiffman et al. 1970). differences in the response mode are significant. This suggests that there may be complexities within each mode that the present procedure has not uncovered. However. it is reasonable to conclude from the present study that the choice of response mode. when experimental conditions are similar to the present one. can be primarily determined by the demands of the experimental design and apparatus. For example. in cases where latency of response measures are recorded. where lighting or visual cues are degraded. or where reports of extensive distances are required (e.g., Gibson. Bergman. \& Purdy. 1955: Ferris, 1972). it is more efficient. practical, and perhaps necessary to employ an absolute estimate mode. In contrast, where research focus is on the relation between two stimuli or in the case where use of a standard-size stimulus is a requisite to comparisons between a series of stimuli (as with geometric illusions). a matching technique should be employed. Generalizing from the stimuli and procedures described herein. the basic results obtained by both response modes would be comparable.

\section{REFERENCES}

Baird. J. C. Retinal and assumed size cues as determinants of size and distance perception. Journal of Experimental Psychology. 1963, 66, 155-162.

Bolles, R. C.. \& Bailey, D. E. Importance of object recognition in size constancy. Journal of Experimental Psychology. 1956. $51,222-225$
Churchill. A. V. Effect of mode of response on judgment of familiar size. Journal of Experimental Psychology. 1962.64. $198-199$

Colhart. M. Effects of two kinds of distance information on visual judgments of absolute size. Nature, 1969. 221. 383.

Epstein. $W$. Perceived depth as a function of relative height under three background conditions. Journal of Experimental Psychology, 1966, 72, 335-338.

Ferris. S. H. Motion parallax and absolute distance. Journal of Experimental Psychology. 1972, 95, 258-263.

Fillenbaum. S.. Schiffman. H. R.. \& Butcher. J. Perception of off-size versions of a familiar object under condition of rich information. Journal of Experimental Psychology, 1965, 69. 298-303.

Garner. W. R., \& Hake, H. W. The amount of information in absolute judgments. Psychological Review, 1951, 58, 446-459.

Gibson, E. J. Bergman, R \& Purdy, J. Effect of prior training with a scale of distance and absolute and relative judgments of distance over ground. Journal of Experimental Psychology. $1955,50.97-105$.

Gogel, W. C., \& Newton, R. E. Perception of off-sized objects. Perception \& Psychophysics, 1969, 5. 7-9.

Krantz, D. L., \& Campbell, D. T. Separating perceptual and linguistic affects of context shifts upon absolute judgments. Journal of Experimental Psvchology, 1961.62.35-42.

Leibowitz. H. W.. \& Hariey, L. O. The effect of instructions. environment, and type of test object on matched size. Journal of Experimental Psychology. 1969, 81, 36-43.

McKennell. A. C. Visual and familiar size: Individual differences. British Journal of Psvchology, 1960,51.27-35.

Miller, C. A., \& Engen. T. Context effects on absolute judgments of length. Journal of Experimental Psychology, 1960, 59 . 276-277.

Over, R. Size and distance estimates of a single stimulus under different viewing conditions. American Journal of Psychology. 1963, 76, 452-457.

Schiffman. H. R. Size-estimation of familiar objects under informative and reduced conditions of viewing. American Journal of Psychology. 1967. 80, 229-235.

Schiffman, J. R.. Goldstein. J., \& E. Aroksaar, R. Response language and context effects. Psychonomic Science, 1970. 20, $127-128$.

Slack. C. W. Familiar size as a cue to size in the presence of conflicting cues. Journal of Experimental Psychology. 1956, 52. $194-198$

(Received for publication July 16. 1973.)

\section{The effect of frequency and number of pairs in a verbal discrimination task*}

\author{
SLE SAVAGE and N. JACK KANAK: \\ Lniversity of Oklahoma. Vorman. Okla. 73069
}

The assumption, derived from the frequency theory of verbal discrimination learning, that list length does not affect verbal discrimination learning proficiency was tested. Results indicated that (a) the number of correct items to be learned does affect learning proficiency significantly when the differential frequency cue is held constant; (b) previous findings reported by Ekstrand, Wallace, and Underwood (1966), that a 20-pair list involving 10 right items repeated twice is superior to a

\footnotetext{
* A paper based on the present study was read by the senior author at the Annual Meeting of the Oklahoma State Psychological Association. Oklahoma City, November 1971, and was awarded first prize in the graduate student competition. This research was supported in part by the Faculty Research Fund of the University of Oklahoma.

$\div$ Requests for reprints should be addressed to $\mathrm{N}$. Jack Kanak. Department of Psychology. University of Oklahoma. Norman. Okla. 73069
}

20-pair control group with no repeated items, may have been due, at least in part, to the fewer number of items to be learned and not solely to the larger differential frequency cue.

The frequency theory (Ekstrand. Wallace. \& Underwood. 1966) of verbal discrimination (VD) learning maintains that $S$ learns a VD list by means of the cue provided by differential frequency unit accruals to intrapair right $(\mathrm{R})$ and wrong $(\mathrm{W})$ items. That is. $\mathrm{S}$ pronounces and rehearses the $R$ item more than the $W$ item. thereby building up an intrapair subjective frequency differential in favor of the $R$ item. As Ekstrand et al point out. the frequency theory predicts that increasing the number of pairs in a VD list should have no effect on the number of trials required to learn the lists. provided that an increase in list length is not accompanied by an increase in the number of interitem associations. 